\title{
How Culturally Appropriate Is the Communicative Approach with Reference to the Chinese Context?
}

\author{
Dongyu Zhang ${ }^{1}$, Yingxia $\mathrm{Li}^{1}$, Yafei Wang ${ }^{2}$ \\ ${ }^{1}$ School of Software, Dalian University of Technology, Dalian, China \\ ${ }^{2}$ School of Grammar, North China University of Technology, Beijing, China \\ Email: zhangdongyu@dlut.edu.cn
}

Received June $23^{\text {rd }}$, 2013; revised July $23^{\text {rd }}$, 2013; accepted July 30 ${ }^{\text {th }}$, 2013

Copyright (C 2013 Dongyu Zhang et al. This is an open access article distributed under the Creative Commons Attribution License, which permits unrestricted use, distribution, and reproduction in any medium, provided the original work is properly cited.

\begin{abstract}
This paper first discusses the Chinese culture of teaching and learning and then further explores the appropriateness of adopting CLT through explorations into the past research on CLT in China. Finally, due to numerous cultural factors and difficulties in adapting CLT, this paper suggests an alternative approach by introducing the Context Approach, before a conclusion is drawn.
\end{abstract}

Keywords: Chinese Culture; Social Context; CLT; Context Approach

\section{Introduction}

Communicative Language Teaching (CLT) has probably become a prominent methodology and a guide for syllabus design in various EFL contexts. It has been recognized that CLT is an advanced methodology with strengths in developing communicative competence and enhancing learner autonomy (e.g., Littlewood, 1981; Li, 1984; Bax, 2003). With regard to the Chinese context, there is a view that CLT should be adopted to promote language teaching for the following two reasons ( $\mathrm{Li}$, 1984). First, the "perceived" Chinese teaching methods mentioned in some literature (e.g., Harvey, 1985; Anderson, 1993), such as grammar-translation method, have been criticized for their weakness in developing students' oral communicative skills in actual language use (Li, 1984). Second, with more and more politically and economically prosperous development of China, such as the events of the Olympics in 2008 and World Expo in 2010, English is gaining more importance. Chinese language teaching has undergone a series of innovations in terms of modernizing teaching methodology and revising the teaching objectives of which communicative competence should be given more importance. In 2003, the Chinese ministry of Education proposed new College English Curriculum Standards. This has stimulated innovations in English teaching in 180 key universities. Take Suzhou University as an example: it requires that all the graduates must pass an oral English test as well as a written test in order to get a degree. From the above discussion, it seems both Chinese researchers and teachers are inclined to adopt CLT as the "right" approach for China. However, it should be highlighted that CLT is based on Western settings; it is still arguable how culturally appropriate it is regarding Chinese culture of teaching and learning. This article will set out to explore this question.

The structure of this paper is as follows: I will first discuss the Chinese culture of teaching and learning. In the first part, I will compare the role of teachers in Chinese traditional English teaching and CLT in view of their teaching values and their teaching behaviors; in the second part, I will examine the Chinese students' learning style of English and the learning process of CLT; in the third part, a brief introduction of social context will be presented. Based on the analysis in the previous section, I will then further discuss the appropriateness of adopting CLT through explorations into past research on "CLT in China." Finally, due to numerous cultural factors and difficulties in adapting CLT, I will suggest an alternative approach by introducing the Context Approach (Bax, 2003), before a conclusion is drawn.

\section{Chinese Culture of Teaching and Learning}

The two terms "Chinese culture" and "culture of teaching and learning" should be defined at the very beginning. For purposes of this article, Chinese culture is discussed in a broad sense, of which "culture" is defined as "a historically transmitted pattern of meaning embodied in symbols, a system of inherited conceptions expressed in symbolic forms by means of which people communicate, perpetuate and develop their knowledge about the attitude towards life" (Geertz, 1979: p. 89). As for the term "culture of teaching and learning," it specifically refers to a series of dynamic processes that reflect the core values of teachers' and students' socialization into classroom interaction, their ways of acquiring appropriate knowledge and skills, and attitudes about the target cultures (Cortazzi \& Jin, 1999: p. 196). In this section, Chinese culture of teaching and learning will be discussed with focuses on the role of Chinese teachers of EFL and students' learning style of English.

\section{The Role of Chinese Teachers of EFL}

The role of Chinese teachers will be examined from two perspectives: the perceived values and perceptions of Chinese teachers embedded in the Chinese traditional culture, and the 
role of Chinese teachers of EFL and accordingly their consequent teaching behaviors, as compared to those of CLT teachers based on Littlewood (1981).

The values and perception of being a teacher embedded in Chinese traditional culture can be illustrated in the following two proverbs. First, “师道尊严不可侵犯” (Teachers' views and dignity should not be attacked), which shows that teachers are regarded and respected as authority figures who should not be challenged in a hierarchical Chinese society. The other one is “一日为师, 终身为父” (He who teaches me may be considered my father-figure for life). This proverb illustrates that a teacher is regarded as one of the most influential persons in a student's life. In addition, they are also regarded as the source of knowledge (Jin \& Cortazzi, 1998).

The teachers' specific teaching practice can be found in another Chinese saying “传道授业解惑也,” which literally means "telling students moral standards, teaching knowledge, and answering questions." Concerning the teaching behaviors of Chinese language teachers, these traditional perceived views of teaching practice can be identified in the present language teaching. First, it appears that Chinese teachers of EFL need to prepare educational materials and activities that can best benefit students' understanding of life and moral standards. Second, teachers teach knowledge (e.g., explaining grammar points) and make every effort to make students understand the language points. This is supported by other researchers. For instance, Hird (1995: p. 23) mentions that Chinese teachers offer students a meticulous analysis of meaning in all its minute detail, which leads to a painstaking understanding of every language item in which students' individual interpretation is not highly accurate. Finally, answering questions and correcting students' mistakes is another characteristic of Chinese teachers of EFL. Furthermore, it is considered to be shameful if a teacher cannot correct the mistakes or answer the questions (Harvey, 1985).

From the above-mentioned teachers' values and teaching behaviors, Chinese teachers' role can be different. They are guides for students' future lives. They are also the knowledge transmitters and students are the receivers (Scollon, 1999). In addition, they are the dominators of the whole learning process. However, it should be noted that they also play other roles, such as classroom organizer, which will not be further discussed in this paper.

There are some obvious differences between traditional teachers and CLT teachers in terms of the role they play, according to Littlewood (1981) and the above discussion. The main difference is that the CLT teachers are the "facilitators of learning" who may decide not to correct mistakes, whereas Chinese teachers are more likely to be "instructors" and "dominators" in the learning process. CLT teachers offer stimulus and experience and have no direct control over students. In fact, CLT teachers need to recognize that "learning does not only take place as a direct result of... [their] own instructions” (Littlewood, 1981: p. 92). Chinese teachers play a very important role in the whole learning process and have direct control over students because they are the main source of language knowledge.

These values and perceived role of Chinese teachers are so rooted that they have become a barrier to adopting a new methodology, according to the literature (Orton, 1990; Ellis, 1996; Lewis \& McCook, 2002; Bax, 2003). For instance, Orton (1990) discovered when she was giving a training course in China that Chinese teachers need to undergo changes in their behaviors but also in their values in order to adopt a new methodology. She says: "On reflection it seems that for the Chinese to adopt the approach proposed, they would not only have to do more of, better and perhaps a little differently, what they had always done, but they would also have to make radical changes to some of their basic beliefs, values and consequent ways of acting” (1990: p. 2).

\section{Chinese Students' Learning Style of English}

China is such a large country with numerous variables and differences in individual learning style. It is impossible to present or generalize about the typical learning style of English. However, it might be possible to point out some common elements learners share in learning English, which have been influenced by the continuous traditional culture. Here, I would like to discuss two points. First, as Anderson (1993) discovered, Chinese students learn to read, write, speak, and then comprehend aurally in exactly the reverse order stressed by Western pedagogy. Reading and rote learning are particularly emphasized in learning a language in Chinese schools, which can be traced back to thousands of years as proved by Chinese proverbs “读书百遍，其义自通” (Read a book a hundred times and then the meaning of the book will come out) and “熟读唐诗三 百首, 不会写诗也会吟” (If you have been reading and are familiar with three hundred Tang Dynasty [0618AD-0907AD] poems, you will be able to read a poem out loud even though you cannot compose one). Quite a number of Chinese students believe that repeated reading, imitating the teacher, and reciting can be helpful to English learning since it has long been proved by their L1 learning. Another feature of Chinese students' language learning is that Chinese students think of themselves as "being 'active', but not necessarily verbally, even in a language class” (Jin \& Cortazzi, 1998: p. 104). Jin and Cortazzi explain that Chinese students "participate" by listening, by thinking (questioning in mind), by asking questions after class, and by discussing with each other after class. These learning features do not coincide with the learning process of CLT.

In CLT, one of the main features of learning process is that the learners learn by working on various communicative activities structured to suit all levels of ability. These activities are learner-directed activities; in other words, the learners themselves conduct the interactions with or without teachers' support (Littlewood, 1981). The communicative activities are based on Vygotskian "Scaffolding Theories," and ideas of natural learning and providing learners with a learning context. For the former, it has been found out that learners can learn more through interactions with their peers in communicative activities (Donato, 1994). In terms of natural learning, Littlewood (1981: p. 92) points out that learners should follow a sequence of learning determined by their own natural process (or "internal syllabus"). A context supporting learning is also emphasized in CLT by conducting pair or group work. In all, the CLT is a learner-centered approach with emphasis on learner autonomy and interaction rather than simply on teacher-centered direction (Maley, 1984).

According to my experience, the biggest problem for Chinese students to accept CLT is that they may find it hard to change their ways of learning, which are still being required and used in learning other subjects. Another problem lies in their dependence on teachers' knowledge transmission rather than other ways of learning; for example, learning through co- 
operative activities. In addition, both Anderson (1993) and Rao (2002) claim that Chinese students' attitude towards communicative activities is another barrier. Chinese learners take learning seriously and tend to regard communicative activities as games for entertainment rather than a learning tool.

\section{Social Context}

The social context should be considered when discussing the appropriateness of CLT. In China, English is still regarded as a foreign language rather than a second language. This may result in a conflict for most learners between Chinese situation and the communicative approach since it is hard to get access to an authentic environment (Ellis, 1996). Another constraint will be current English examinations that emphasize grammatical structures and pay little attention to more communicative skills (Barlow \& Lowe, 1985; Harvey, 1985). The examinations and Chinese teachers' reluctance to take risks (Anderson, 1993) account for their hesitancy to accept Canale \& Swain's model of CLT (1980) that seems to equate process with content and emphasize meaning rather than form.

\section{Summary}

The equations are an exception to the prescribed specifica In the previous section, I discussed Chinese situations through cultural perspectives; namely, the role of teacher, learners' learning styles and social context, which seem to be culturally contradictory to those embedded in CLT. It therefore can be assumed that Chinese teachers, learners, and examination systems need to undergo great or even fundamental changes in order to make CLT workable and effective. However, how can Chinese teachers adopt CLT to match Chinese situations and in what ways can they themselves and learners make changes to adopt CLT? Are these changes possible? Moreover, since it might be difficult to change the rooted Chinese culture of teaching and learning, is there an alternative approach to reach the same objective (communicative competence) while maintaining harmony with Chinese situations? These questions need to be further explored in the next section when examining the results of past research on "CLT in China" and Bax's Context Approach.

\section{Review of Past Research}

Much research about CLT in the Chinese context has been done in the past 20 years. Nevertheless, the results seem to be rather unsatisfactory and there is no agreement on employing CLT. The earliest research was carried out by $\mathrm{Li}$ in a university. In 1984, she presented a brave idea that CLT should be and could be adopted in China, especially for her students majoring in English. However, it is still arguable whether her approach is exactly a "communicative approach" (Harvey, 1985), since she only examined the importance of authentic material and great amount of language input. Some other research was done by foreign researchers and teachers. Anderson (1993) claimed that the greatest contribution made by English native speakers is their insistence on using CLT in China and CLT is practical as long as foreign teachers adapt CLT to match the Chinese situation. One of his example shows that foreign teachers should take Chinese students' learning style into account and discuss with learners about their learning needs. These foreign teachers' experience might be helpful. However, the limitation in his study is that those foreign teachers work in institutions where the situation may be different from what most Chinese teachers are facing. Furthermore, Chinese teachers have to consider their learners' expectations and attitudes towards Chinese teachers and constraints, such as the existing examination system. Anderson only points out the obstacles, such as various cultural factors and social constraints, rather than presenting ways of solving those problems. A more recent study has been done by Rao (2002). She reports that only by reconciling communicative and non-communicative activities can Chinese students benefit from CLT. This result does not mean much with regard to the Chinese context, for Rao herself discovers that most Chinese classrooms do not use CLT due to many other reasons than students' attitudes towards communicative activities. Though these research results do not give Chinese teachers much confidence in adopting CLT, it is not wise to show a completely negative attitude to CLT since there are variables of different situations within the Chinese context. However, the fact is that little evidence shows the possibilities of overcoming these obstacles and there is no conclusion that CLT can work in most Chinese classrooms. It therefore may be a better idea to turn to other approaches that might better benefit Chinese language teaching.

Bax claims in his article (2003) that the fatal flaw of CLT is its neglect of the context that is a significant determiner of the success or failure of learners. He then proposes a new approach, a Context Approach, and presents a contrast between CLT and the Context Approach.

In Bax's view, the Context Approach takes the context of a particular situation, other factors, and other methods into account, compared to CLT and the Lexical Approach. The feature of this approach (see Appendix) is that it places the priority on the learning context, including learner variables, before other priorities, such as teaching approach and language focus. This approach might be helpful for the Chinese context that has a number of variables and situations. It can be used as an analytical tool to help Chinese teachers to be aware of their own particular context. However, this approach seems to assume that teachers are all competent in making different pedagogical decisions suit a particular context. However, such an assumption could be problematic as a considerable number of teachers are not familiar with other alternative methods except the traditional methods. A possible way to solve this problem is for teacher education and training programs to focus on helping teachers analyze their own situations and methodology training.

\section{Conclusion}

This paper has discussed the appropriateness of CLT from the perspective of culture of teaching and learning. From the discussion of the role of Chinese teachers, learning styles, and social context, which have found to have conflicts with those embedded in CLT, it argued that CLT is not culturally appropriate for the Chinese context. Moreover, it is hard for Chinese language teaching to undergo changes to adopt CLT and there is little support from the past research. This paper has also made attempts to explore an alternative approach, the Context Approach. This approach seems to be a corrective to the shortcoming of CLT; that is, neglecting context. It emphasizes on identifying a suitable approach based on context analysis. This approach might be useful because it can help Chinese teachers critically analyze their own teaching situation when undertak- 
ing innovations, rather than westernizing methodology. Therefore, since it is a new approach, further investigations are needed before putting it into practice.

\section{REFERENCES}

Anderson, J. (1993). Is a communicative approach practical for teaching English in China? Pros and cons. System, 21, 471-480. http://dx.doi.org/10.1016/0346-251X(93)90058-O

Barlow, T. E., \& Lowe, D. (1985). Chinese reflections: Americans teaching in the People's Republic. New York: Praeger.

Bax, S. (2003). The end of CLT: A context approach to language teaching. ELT Journal, 57, 278-287. http://dx.doi.org/10.1093/elt/57.3.278

Byram. M., \& Fleming, M. (1998). Language learning in intercultural perspective: Approaches through drama and ethnography. Cambridge: Cambridge University Press.

Canale, M., \& Swain, M. (1980). Theoretical bases of communicating approaches to second language teaching and testing. Applied Linguistics, 1, 1-47. http://dx.doi.org/10.1093/applin/1.1.1

Cortazzi, M., \& Jin, L. X. (1999). Cultural mirrors: Materials and methods in the EFL classroom. In E. Hinkel (Ed.), Culture in second language teaching and learning (pp. 196-219). Cambridge: Cambridge University Press.

Donato, R. (1994). Collective scaffolding in second language learning. In J. P. Lantolf, \& G. Appel (Eds.), Vygostkian approaches to second language research (pp. 33-56). New Jersey: Ablex.

Ellis, G. (1996). How culturally appropriate is the communicative approach? ELT Journal, 50, 213-218.

http://dx.doi.org/10.1093/elt/50.3.213

Geertz, C. (1979). Meaning and order in Moroccan society: Three essays in cultural analysis. Cambridge: Cambridge University Press.

Harvey, P. (1985). A lesson to be learned: Chinese approaches to language learning. ELT Journal, 39, 7-9.

http://dx.doi.org/10.1093/elt/39.3.183

Hinkel, E. (1999). Culture in second language teaching and learning.
Cambridge: Cambridge University Press.

Hird, B. (1995). How communicative can language teaching be in China? Prospect, 10, 21-27.

Jin, L. X., \& Cortazzi, M. (1998). The culture the learner brings: A bridge or a barrier? In M. Byram, \& M. Fleming (Eds.), Language learning in intercultural perspective: Approaches through drama and ethnography (pp. 98-118). Cambridge: Cambridge University Press.

Lantolf, J. P., \& Appel, G. (1994). Vygostkian approaches to second language research. New Jersey: Ablex.

Larson, P., Judd, E., \& Messerschmitt, D. (1984). On TESOL '84: A brave new world for TESOL. Selected Papers from the 18th Annual Convention of TESOL (pp. 121-134). Houston, TX.

Lewis, M., \& McCook, F. (2002). Cultures of teaching: Voices from Vietnam. ELT Journal, 56, 146-152. http://dx.doi.org/10.1093/elt/56.2.146

Li, X. J. (1984). In defence of the communicative approach. ELT Journal, 38, 2-13. http://dx.doi.org/10.1093/elt/38.1.2

Littlewood, W. (1981). Communicative language teaching: An introduction. Cambridge: Cambridge University Press.

Maley, A. (1984). On chalk and cheese, babies and bathwater and squared circles: Can traditional and communicative approaches be reconciled? In P. Larson, E. Judd, \& D. Messerschmitt (Eds.), On TESOL '84: A brave new world for TESOL. Selected papers from the Eighteenth Annual Convention of TESOL (pp. 6-11). Houston, TX.

Orton, J. M. (1990). Educating the reflective practitioner in China: A case study in teacher education. Unpublished Doctoral Dissertation, Melbourne: La Trobe University.

Rao, H. Z. (2002). Chinese students' perceptions of communicative and non-communicative activities in EFL classroom. System, 30, 85-105. http://dx.doi.org/10.1016/S0346-251X(01)00050-1

Scollon, S. (1999). Not to waste words or students: Confucian and Socratic discourse in the tertiary classroom. In E. Hinkel (Ed.), Culture in second language leaching and learning (pp. 13-27). Cambridge: Cambridge University Press. 


\section{Appendix}

The context approach to language teaching: priorities and procedures.

\section{First Priority: Context}

Step 1: Teacher will develop analytical tools for analyzing and understanding the learning context.

Step 2: Teacher will analyze the context carefully and systematically as far as possible. This includes enhanced awareness of these areas. As shown in Table A1.

\section{Second (or Third) Priority: Teaching Approach}

This may involve decisions related to methodological aims and means, including decisions relating to: syllabus, classroom seating, materials, methods, student groupings, etc.

\section{Third (or Second) Priority: Language Focus}

This will involve decisions related to the aspect of language to be focused on, such as lexis, for example, or phonology, or grammar.

(Cited from Bax, 2003, 287)
Table A1.

An analysis of learning context.

\begin{tabular}{cc}
\hline Individuals & Classroom culture \\
\hline Personal differences & Group dynamics \\
Learning styles & Group motivation \\
Learning strategies & Classroom environment \\
Personal motivation & School environment \\
\hline Local culture & National culture \\
\hline Regional differences & Political context \\
Status for teacher and students in community & Religious context \\
Attitude and behavior of parents & Social context \\
Local environment & National environment \\
\hline
\end{tabular}

